\title{
An animal model for progressive multifocal leukoencephalopathy
}

\author{
Sheila A. Haley and Walter J. Atwood \\ Department of Molecular Biology, Cell Biology, and Biochemistry, Brown University, Providence, Rhode Island, USA.
}

\begin{abstract}
JC virus (JCV) causes progressive multifocal leukoencephalopathy (PML), a demyelinating disease in humans. The disease, once considered fatal, is now managed with immune reconstitution therapy; however, surviving patients remain severely debilitated. Until now, there has been no animal model to study JCV in the brain, and research into treatment has relied on cell culture systems. In this issue of the $J C I$, Kondo and colleagues developed a mouse model in which human glial cells are engrafted into neonatal mice that are both immunodeficient and deficient for myelin basic protein. When challenged intracerebrally with JCV, these mice exhibit some of the characteristics of PML. The establishment of this chimeric mouse model is a significant advance toward understanding the mechanism of JCV pathogenesis and the identification of drugs to treat or prevent the disease.
\end{abstract}

induce genetic instability in transformed cells. Results from studies with these cell cultures made it clear that astrocytes and glial precursors could both support viral replication. It should be noted that none of these cultures contained oligodendrocytes, as these postmitotic cells were likely eliminated during cell passaging and the technology to derive them from glial precursors had not yet been developed.

\section{Diagnosis and natural history of the virus}

Definitive diagnosis of PML was markedly advanced in 1987 by the development of an in situ hybridization assay that used labeled JCV-specific DNA probes $(7,8)$. These new assays confirmed that oligodendrocytes were the major target of virus infection in the brain, as replicating JCV DNA was readily detected in these cells. Astrocytes occasionally scored positive in these assays, and in one case, cells from the bone marrow of a PML patient tested positive for the virus (9), leading to the hypothesis that lymphoid cells may traffic virus from the periphery to the CNS to cause PML. Peripheral sites of viral persistence include the kidney and possibly bone marrow $(10,11)$. In the kidney, the virus has an archetypal regulatory region that predominates in this tissue, but is rarely seen in blood or in brain. Moreover, in bone marrow and blood, the virus exhibits numerous and diverse rearrangements of the regulatory region, and it is this form of the virus that is associated with CNS disease and has been referred to as PMLtype JCV (12, 13). Additional mutations occur in the coding region of the major capsid protein VP1 during high-level replication of the virus in CNS tissue, and these mutations are specific for PML. Thus, persistent virus in kidney is thought to undergo numerous rearrangements that are perhaps driven by recombinase enzymes present in lymphoid cells which then traffic the virus to the CNS, where high-level replication leads to additional mutations that 


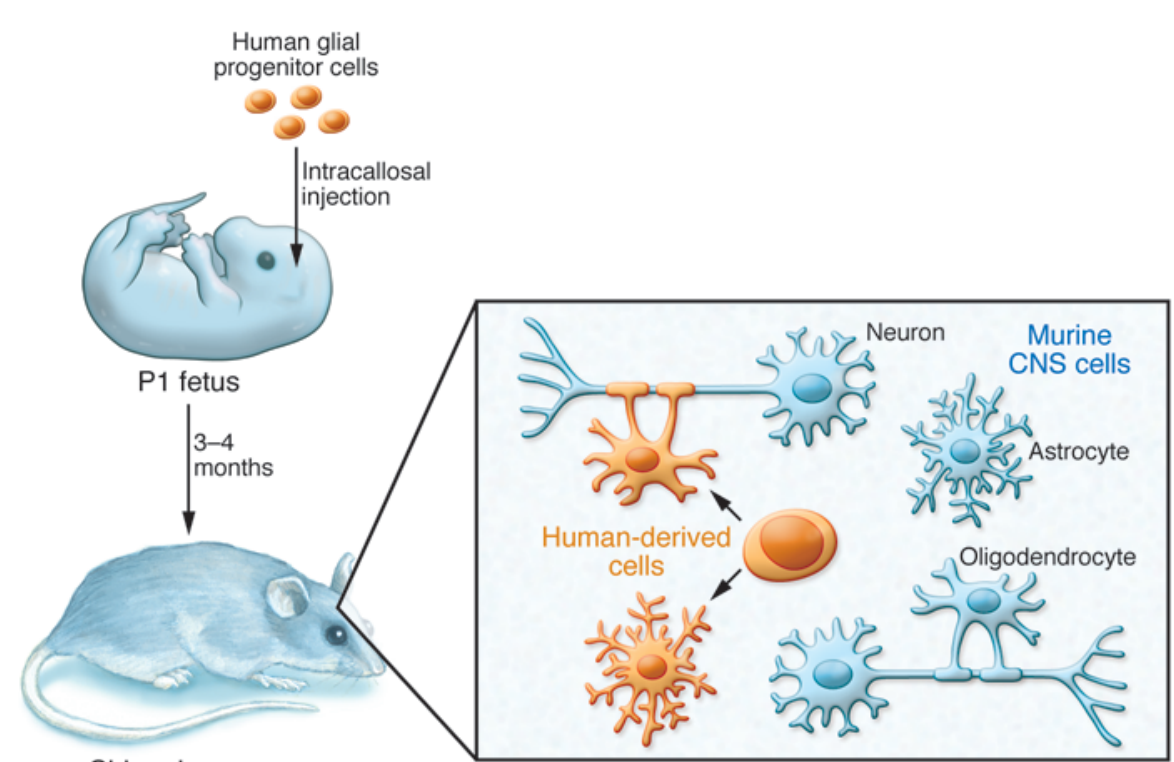

Chimeric mouse
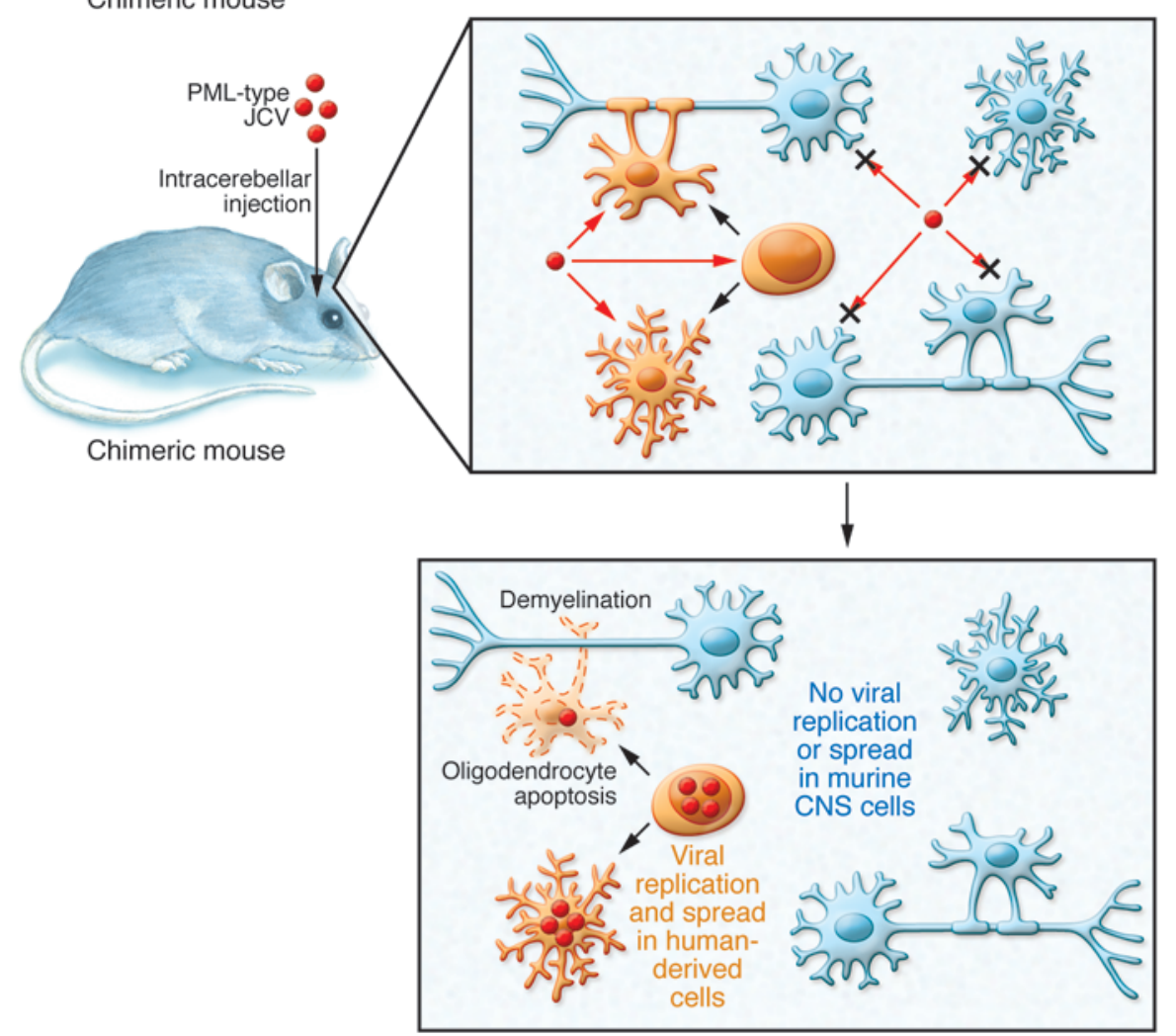

likely favor viral spread within the brain. The current model developed by Kondo and colleagues involves direct inoculation of the rearranged or PML-type JCV into brain parenchyma, thus bypassing the early stages of persistence and viral evolution that lead to pathogenesis (14). The fact that the authors observed and documented mutations in VP1 from the injected virus make it clear that these changes can come about after viral penetration of CNS tissue and are likely due to a high level of repli-
Figure 1. Chimeric mice provide a murine model of PML. Human glial progenitor cells are injected into the corpus callosum of neonatal mice. Over the course of 3-4 months, the human glial precursors divide and differentiate into glial cells, such as astrocytes and oligodendrocytes, that incorporate into the murine CNS. Injection of PML-type JCV into the chimeric mouse brain results in infection of human-derived cells, but not murine cells. JCV readily infects and replicates in human glial precursors and humanderived astrocytes. In this model, JCV infects human-derived oligodendrocytes but does not readily replicate in them, instead inducing apoptosis that results in demyelination.

increased during the AIDS pandemic, with the disease occurring in $2 \%-5 \%$ of HIV-infected individuals (17). In 2005, the first cases of PML appeared in patients that were being treated with humanized monoclonal antibodies that block leukocyte trafficking into inflamed tissues for the treatment of inflammatory diseases, such as multiple sclerosis, rheumatoid arthritis, and Crohn's disease (18-20). The rapid rise in PML incidence led many investigators to develop and test a variety drugs for efficacy against this devastating disease (21-23). As no animal models existed, these investigations were restricted to cultures of either primary or established cell lines (24-29). The lack of an animal model for PML has been a major limitation for the development of effective therapies for people who have or are at risk for developing PML.

\section{The model}

In this issue, Kondo and colleagues have succeeded in developing a mouse with humanized glia (14). This remarkable achievement was brought about by implantation of primary human glial progenitor cells into neonatal immunodeficient, myelin-deficient ( $R a g 2^{-/-} M b p^{\text {shi/shi}}$ ) mice. These mice developed white matter derived from the human glial cell precursors. Intracerebral inoculation of these chimeric mice with JCV led to virus replication and spread within the human white matter tracts. In this model, astrocytes and glial progenitors were shown to be the cell types most susceptible to virus infection, and oligodendroglial cell death, which was accompanied by demyelination, occurred by apoptosis rather than direct killing of these cells by the virus (Figure 1). Remark- 
ably, the authors were able to demonstrate an evolution of viral sequences during disease progression in these mice that reflected the biology of disease in PML patients. Moreover, infection of the chimeric mice with JCV mutants derived from human patients also led to viral spread and disease $(30,31)$. This latter point is interesting, as mutant virus arising in human patients seems unable to recognize sialic acid-containing receptors for the virus (32, 33). These viruses must evolve to use alternative means of infection and spread, the mechanisms of which are under investigation in several labs.

The power of the model developed by Kondo et al. (14) is the ability to finally test specific drugs and other treatments for efficacy against PML. In order for drugs to be efficacious, it will be imperative for them to cross the blood-brain barrier of the mouse to inhibit viral spread and, ultimately, disease progression. The authors make a very strong argument that JCV does not replicate in oligodendrocytes, but rather kills them by inducing apoptosis. This observation is intriguing; however, it may be unique to the authors' specific mouse model, as years of work with human tissues clearly indicates that the primary target for lytic replication of JCV in the human brain is the mature oligodendrocyte. Kondo and colleagues also demonstrated that the virus does not need oligodendrocytes to spread (14). This point is not surprising, as JCV has been propagated for years in primary or established cell cultures that do not contain oligodendrocytes. It is important to note that while the engrafted cells in this mouse model are human, all of the other cells, such as kidney and lymphoid cells, remain of mouse origin and are therefore not susceptible to infection with the virus. This limitation will preclude studies to define routes of primary infection, factors involved in the establishment of latency or persistence, and contributions of different virus strains to disease manifestations. Ultimately, this model will not be able to elucidate how the virus is spread from the periphery to the CNS. In future studies, one could imagine humanizing the immune system of these mice and, for example, investigating the hypothesis that lymphoid cells are responsible for trafficking the virus to the CNS. Although an animal system to study JCV pathogenesis from the initial site of infection through to PML remains elusive, the model generated by Kondo and colleagues is a major breakthrough in the field.

\section{Acknowledgments}

Work in the authors' laboratory is supported by NIH grants R01NS043097 (to W.J. Atwood) and P01NS065719 (to W.J. Atwood). Core facilities at Brown are supported by NIH grant P30GM103410 (to W.J. Atwood).

Address correspondence to: Walter J. Atwood, Department of Molecular Biology, Cell Biology and Biochemistry, Brown University, 70 Ship Street, Providence, Rhode Island 02903, USA. Phone: 401.863.3116; E-mail:Walter_Atwood@brown.edu.

1. Astrom K, Mancall E, Richardson EP Jr. Progressive multifocal leukoencephalopathy. Brain. 1958;81(1):93-127.

2. Richardson EP Jr. Progressive multifocal leukoencephalopathy. N Engl J Med.1961;265:815-823.

3. Mollenhauer HH. Plastic embedding mixtures for use in electron microscopy. Stain Technol. 1964;39:111-114.

4. Padgett B, ZuRhein G, Walker D, Echroade R, Dessel B. Cultivation of papova-like virus from human brain with progressive multifocal leukoencephalopathy. Lancet. 1971;1(7712):1257-1260.

5. Major EO, Miller AE, Mourrain P, Traub RG, de Widt E, Sever J. Establishment of a line of human fetal glial cells that supports JC virus multiplication. Proc Natl Acad Sci U S A. 1985;82(4):1257-1261.

6. Mandl C, Walker DL, Frisque RJ. Derivation and characterization of POJ cells, transformed human fetal glial cells that retain their permissivity for JC Virus. J Virol. 1987;61(3):755-763.

7. Aksamit AJ, Major EO, Ghatak NR, Sidhu GS, Parisi JE, Guccion JG. Diagnosis of progressive multifocal leukoencephalopathy by brain biopsy with biotin labelled DNA:DNA in situ hybridization. J Neuropathol Exp Neurol. 1987;46(5):556-566.

8. Houff SA, Katz D, Kufta CV, Major EO. A rapid method for in situ hybridization for viral DNA in brain biopsies from patients with AIDS. AIDS. 1989;3(12):843-845.

9. Houff SA, et al. Involvement of JC virus-infected mononuclear cells from the bone marrow and spleen in the pathogenesis of progressive multifocal leukoencephalopathy. N Engl J Med. 1988;318(5):301-305.

10. Ferenczy MW, et al. Molecular biology, epidemiology, and pathogenesis of progressive multifocal leukoencephalopathy, the JC virus-induced demyelinating disease of the human brain. Clin Microbiol Rev. 2012;25(3):471-506.

11. Berger JR, Khalili K. The pathogenesis of progressive multifocal leukoencephalopathy. Discov Med. 2011;12(67):495-503.
12. Jensen PN, Major EO. A classification scheme for human polyomavirus JCV variants based on the nucleotide sequence of the noncoding regulatory region. J Neurovirol. 2001;7(4):280-287.

13. Johnson EM, Wortman MJ, Dagdanova AV, Lundberg PS, Daniel DC. Polyomavirus JC in the context of immunosuppression: a series of adaptive, DNA replication-driven recombination events in the development of progressive multifocal leukoencephalopathy. Clin Dev Immunol. 2013;2013:197807.

14. Kondo Y, et al. Human glial chimeric mice reveal astrocytic dependence of JC virus infection. J Clin Invest. 2014;124(12):5323-5336.

15. Holman RC, Torok TJ, Belay ED, Janssen RS, Schonberger LB. Progressive multifocal leukoencephalopathy in the United States, 1979-1994: increased mortality associated with HIV infection. Neuroepidemiology. 1998;17(6):303-309.

16. Holman RC, Janssen RS, Buehler JW, Zelasky MT, Hooper WC. Epidemiology of progressive multifocal leukoencephalopathy in the United States: analysis of national mortality and AIDS surveillance data. Neurology. 1991;41(11):1733-1736.

17. Major EO, Amemiya K, Tornatore CS, Houff SA, Berger JR. Pathogenesis and molecular biology of progressive multifocal leukoencephalopathy, the JC virus-induced demyelinating disease of the human brain. Clin Microbiol Rev. 1992;5(1):49-73.

18. Van Assche G, et al. Progressive multifocal leukoencephalopathy after natalizumab therapy for Crohn's disease. $N$ Engl J Med. 2005;353(4):362-368.

19. Kleinschmidt-DeMasters BK, Tyler KL. Progressive multifocal leukoencephalopathy complicating treatment with natalizumab and interferon beta-1a for multiple sclerosis. $N$ Engl J Med. 2005;353(4):369-374.

20. Langer-Gould A, Atlas SW, Green AJ, Bollen AW, Pelletier D. Progressive multifocal leukoencephalopathy in a patient treated with natalizumab. NEngl J Med. 2005;353(4):375-381.

21. Clifford DB. Progressive multifocal leukoencephalopathy therapy [published online ahead of print September 17, 2014]. J Neurovirol. doi:10.1007/s13365-014-0289-8.

22. De Luca A, et al. Cidofovir in addition to antiretroviral treatment is not effective for AIDS-associated progressive multifocal leukoencephalopathy: a multicohort analysis. AIDS. 2008;22(14):1759-1767.

23. Clifford DB, et al. A study of mefloquine treatment for progressive multifocal leukoencephalopathy: results and exploration of predictors of PML outcomes. J Neurovirol. 2013;19(4):351-358.

24. Kerr DA, Chang CF, Gordon J, Bjornsti MA, Khalili K. Inhibition of human neurotropic virus (JCV) DNA replication in glial cells by camptothecin. Virology. 1993;196(2):612-618.

25. Brickelmaier M, et al. Identification and characterization of mefloquine efficacy against JC virus in vitro. Antimicrob Agents Chemother. 2009;53(5):1840-1849.

26. Hou J, Major EO. The efficacy of nucleoside analogs against JC virus multiplication in a persistently infected human fetal brain cell line. J Neurovirol. 1998;4(4):451-456. 
27. Fonseca-Elphick G, et al. The human polyomavirus, JCV, uses serotonin receptors to infect cells. Science. 2004;306(5700):1241-1420.

28. Carney DW, et al. Structural optimization of a retrograde trafficking inhibitor that protects cells from infections by human polyoma- and papillomaviruses. Bioorg Med Chem. 2014;22(17):4836-4847.

29. Nelson CD, et al. A retrograde trafficking inhibitor of ricin and Shiga-like toxins inhibits infec- tion of cells by human and monkey polyomaviruses. MBio. 2013;4(6):e00729-e00713.

30. Reid CE, et al. Sequencing and analysis of JC virus DNA from natalizumab-treated PML patients. J Infect Dis. 2011;204(2):237-244.

31. Gorelik L, et al. Progressive multifocal leukoencephalopathy (PML) development is associated with mutations in JC virus capsid protein VP1 that change its receptor specificity. J Infect Dis.
2011;204(1):103-114.

32. Maginnis MS, et al. Progressive multifocal leukoencephalopathy-associated mutations in the JC polyomavirus capsid disrupt lactoseries tetrasaccharide c binding. MBio. 2013;4(3):e00247-e00213.

33. Neu U, et al. Structure-function analysis of the human JC polyomavirus establishes the LSTc pentasaccharide as a functional receptor motif. Cell Host Microbe. 2010;8(4):309-319. 